\title{
Introduction: It's All Over! Post-digital, Post-internet Art and Education
}

Gila Kolb, Juuso Tervo, and Kevin Tavin

'How big is the internet?' asks an anonymous user in Jodel. ${ }^{1}$ Reading the question on the display of a smartphone, amused by the presumed unanswerability of the question, one scrolls through the answers of other users: 'Without the porn pages, it would fit on a CD' or ' 324 bathtubs.' Since the app does not show this dialogue for longer than 24 hours, one takes a screenshot with a swift, orchestrated movement involving the thumb and the index finger. The image hovers briefly over the home screen only to reappear in the 'My Pictures' folder. As thumbs continue their semi-automated dance on the surface of the phone, this found object

G. Kolb

Schwyz University of Teacher Education, Goldau \& Berne University of the Arts, Goldau, Switzerland

e-mail: gila.kolb@phsz.ch

J. Tervo

Department of Art, Aalto University, Espoo, Finland

e-mail: juuso.tervo@aalto.fi

K. Tavin $(\bowtie)$

Department of Art, Aalto University, Espoo, Finland

e-mail: kevin.tavin@aalto.fi

(C) The Author(s) 2021

K. Tavin et al. (eds.), Post-Digital, Post-Internet Art and Education, Palgrave Studies in Educational Futures, https://doi.org/10.1007/978-3-030-73770-2_1 
immediately continues its journey to another app in a chat to a colleague, who quickly writes back: "Nice start for our Introduction"- a text that is worked on simultaneously in Google Docs. Being behind of schedule, this shared, passing amusement offers a much-needed inspiration to write about the Internet, in the Internet, with the Internet, and through the Internet.

Why begin an introduction for a book about post-internet, post-digital art and education with a narrative that, in its everydayness, seems to make little sense beyond the particular time and place in which this book has been written? The obvious, yet complex, answer is that it is precisely this sense of everydayness surrounding the Internet and its social, technological, material, and bodily extensions that, we, as the editors of this book, find so fascinating and pertinent to art and education today. Being 'all over'-both in terms of being everywhere and functioning like a Midas' touch that, instead of gold, marks everything with an expiration datethe Internet is surely something as perplexing as 324 bathtubs saved in a screenshot.

The Internet, of course, does not simply only mean what we carry around with us-such as a smartphone in our pocket (Meyer 2014, 2020) - but all of its practices, and perhaps the endless entertainment and entanglements, between objects, humans, algorithms, and other nonhuman actors. As jan jagodzinski points out in his chapter in this book, the smartphone has become an entertainment center all on its own: television, music videos, Internet, geographical mapping, and so on, and this mediascape of the twenty-first century places us in a time where cognition takes a back seat, as the time-based material field provides the impulses and signals of transmission through the materialization of digital data.

In the 1990s, we went on the internet and imagined an immersion into the digital world in movies like Tron (1982). Today, the Internet has slipped into our back pockets and thus into the reality of everyday lives, and the sequel of Tron (2010) tells us about an algorithm that escapes its digital boundaries and disappears into the sunset of the real world. This immersion of the internet through smartphones into real life may mean asking the internet or Jodel users a question. The question about the size of the internet is formulated so openly that it can be both serious and a laconic side note, which can be expressed purely for the sake of social interaction. The question was typed into a smartphone 
with minimal tactile activity with a thumb, but strictly speaking, fingertips touched the glass of a minicomputer, and not, as was the case a few years ago, pressing down on plastic buttons. Michel Serres described users who take the operation of the devices for granted and explore the world with it as "thumbelina and tom thumb [Petite Poucette]" (Serres, 2014). According to Serres, however, they are not only distinguished by their ability to operate devices with their thumbs. He notes that they do not share the same concepts of spaces and time.

It is not only the practices of the different technologies connected with the internet that are constantly changing, but also the individuals and groups (and objects) that practice with them. The same device, and even the same apps ${ }^{2}$ can be, and is, used very differently by different people as actors and nonhuman actors, and its use is also bound to peer groups. One could argue, as do many of the authors in this book, that humans (also including those who do not have a smartphone, who use it mainly to make phone calls by holding it to their ear, or by using it with their index finger) are in the middle of a social, political, and technological shift in which digitality and the internet play a significant role. Yet, while this shift also affects how art education is practiced and understood, the global circulation of digital images and their social and political effects are not reducible to a technological apparatus called 'the Internet.' Rather, the shifting landscape of both human and nonhuman activities produces endless social and material entanglements that have overlapping, even conflicting consequences for art education. Indeed, in his chapter in this book, Knochel argues that art education of the future might not be limited to focusing on the Internet or even considerations of producing and consuming media, but to question the capacities of data structures, network formations, and hardware configurations.

At present, from our perspective, it is no longer a question of getting somewhere on the Internet, but of navigating with and through it, and it navigating us. This may sometimes seem magical and sometimes lead to astonishment, or what jagodzinski in his chapter calls sensations, affects, and percepts as peer-generated buzz occurs, a neurosynaptic chemical rush. As Klein, in her essay asks us to consider: Which fantasies and desires are inscribed in technologies and which ones are they in turn producing? For example, with the Sky Guide app, one can see stars under your feet (through the Earth, so to speak), or a Pokémon sits on the kitchen table in the augmented reality version of the app. While this amazement might eventually give away to everyday use and habit-eventually forgotten, or 
no longer magical-it may nevertheless push us to desire something even more magical, some other rush to be experienced within the tightly woven and ever-blurred intersection of online and offline. One may ask, then, what kind of knowledge, effects, magic, astonishment, and boredom do such navigations through and with the Internet produce, now and in the future? What kind of further questions do they pose for art and education in a post-digital, post-internet era?

Within the last decade, 'post-digital' and 'post-internet' have become signifiers attached to artworks, artists, exhibitions, and education practices that deal with the relationship between online and offline, digital and nondigital, as well as material and immaterial. In terms of art, for example, Vierkant (2010) discusses the "physical space in networked culture and the infinite reproducibility and mutability of digital materials" (p. 3). Indeed, Vierkant (2010) not only speaks about post-internet art but also about "Post-Internet culture' (para 1) and "Post-Internet climates" (para 13). In this sense, Vierkant's descriptions apply simultaneously to post-internet art and all of its circumstances.

In what follows, this chapter investigates post-digital and post-internet art and education as a way of taking the present and future of art and education seriously, starting from the radically changed sociotechnological conditions and its consequences. As Zahn points out in his chapter, this is a process that intervenes deeply in the world- and selfrelations, by changing subject configurations, identity, memory practices, social configurations, ways and means of communication, as well as critical references to culture. Resulting from the logic of what Chan (as cited in Scherpe, 2011) has called the "Internet state of mind" (para 37), which suggests in part this fundamentally changed perception of the world, the different sections and the chapters of this book set out to attend to this condition from the perspective of art and its education. Next, we turn to the question of why now.

\section{Why This Book Now?}

One could argue that publishing a book at the end of the second decade in the twenty-first century with the term post-internet in its title may seem awkwardly passé. At least in the so-called artworld, the postinternet already happened; it had its moments (one epitome would be, for example, the 9th Berlin Biennale in 2016, when the term was already used in a derogatory manner), and now, as is custom, it seems time to 
move on to other trends and scenes. For those who see art educators always lagging behind the artworld, this seeming awkwardness might be self-explanatory: when the so-called real work of art is done, art educators and mediators may focus on so-called beating the dead horse as they so often are claimed to do.

However, this book is not meant to be a claim for an entrepreneurial timeliness of the post-internet for art and education any more than a condescending history of a phenomenon. While the post-internet as a catchphrase used in the artworld certainly offers an important point of reference for the discussions at hand, the fact is that the world in which the Internet, as well as digitality in general, have become a 'state of mind' is a world in which art teachers, educators, curators, and mediators (i.e., not only artists) also live and work, and have been for some time now. Yet, since neither the world nor the Internet is simply two tabulae rasae for human activities to occur, but historically, socially, and politically layered and intricately entangled messes of local and global issues and agencies, this state of mind manifests itself quite differently in the various contexts and traditions of art and education.

Hence, instead of promoting a clearly delineated approach to art and education in these post-internet, post-digital times, one of the guiding ideas behind this book has been to gather locally and historically contingent practices and articulations with and through the post-digital and the post-internet. Combining different contexts and different aims, not to mention different styles of writing (i.e., not only the sense of writing but also how one spells out the term post or Post, or Post-, etc.), this book aims to challenge fixed narratives and field-specific ownership of these terms, and explore their potentials as well as limitations when discussing art and education today, and indeed in the future.

This book gathers perspectives on post-digital and post-internet art and education from teachers, educators, theorists, artists, and curators based in Northern Europe and North America. This means that the book addresses the Internet and digitality mainly as they are used and understood in the so-called global North. As Klein and Smith point out in their respective chapters, limiting oneself only to this perspective runs the risk of reproducing a Eurocentric history of art, education, and technology that neglects its own uses and abuses of power. If, indeed, the 'Internet state of mind' has really changed the world in which artists, educators, and curators work and live, it is important to ask, who frames this world and its change, how, and what kind of future(s) this change is expected 
to engender. Asking such questions is precisely what Rousseau and Sternfeld encourage in their chapter in which they envision radical post-digital and post-internet artistic practice and education beyond the corporate spectacle of Silicon Valley capitalism.

Besides artistic and educational practices, the post-internet, post-digital state of mind also affects the way that art and education become conceptualized and theorized, whether together or separately. Going back to the idea that one no longer goes into the Internet but instead navigates with it (or it is in many cases it navigates us unknowingly), the omnipresence of online/offline interfaces requires conceptual and theoretical frameworks that are sensitive to their agencies in schools, galleries, museums, universities, and art studios. For example, as Meyer, in his chapter, argues that hanging onto the Humboldtian subject of Bildung might not be helpful when trying to grasp the interconnectedness of networked subjects and agencies of the post-digital world, meaning that a new theory of subject (or Sujet, as Meyer calls it) is needed. Furthermore, Schütze, in her chapter, agrees by stating that one such aspect would include the subject of education, which has been subjected to transformation and seems to have transgressed even further within the mesh of current conditions to dissolve into complex structures.

\section{The Diversity of Posts}

Throughout this book, we, the editors, made a conscious decision to not demand that the authors write in a unified way when addressing postinternet or post-digital, either separately or together, whether discussing art, space, networks, meanings, etc. As mentioned earlier, this included not only the way the terms were written (i.e., capital letters or small letters, or use of hyphenations or not), but more importantly, the way the terms are defined, given, taken-up, or passed over in each chapter. We agree with Schmidt and Klein, in their respective chapters, when they argue that the term 'post,' in post-internet, does not mean that the internet is over. Instead, we choose to let the diversity of style, form, and use by the authors stand as an answer to the question, 'what might postinternet art and education be?' rather than a definition, for our current times. These answers were drawn from practices-as educators, theorists, researchers and therefore are related to the present. As if chasing 'after the internet' and 'after the digital,' we prefer to leave exposed everything in this book discussed through the lens of post-internet and post-digital, 
and allow the readers to draw their own conclusions about what these terms entail.

We wanted the concepts to be interpreted by the readers, depending on their discursive and performative context, whether they view them as controversial, fragmented, or constantly transmuting. Like Schmidt, in her chapter, we resist the idea that the term 'post' refers to something that always follows something older (although it does owe a debt of some kind), or always points to something new. Instead, we see the prefix 'post' pointing to an entanglement between continuity and discontinuity, where the now delineates a present that is not, prima facie, new. Instead, the post-ness of the present, whether referring to digital or art, may offer a productive critique of both a future-oriented logic that conflates historical progression with a constant production of the new, and an inquiry into how to actualize its potentiality (Tavin \& Tervo, 2018). Instead, in this book, we attempt to follow Bridle's (2012) idea that post-internet and post-digital

is not a space (notional, cyber or otherwise) and it's not time (while it is embedded in it at an odd angle) it is some other kind of dimension entirely [sic]. BUT meaning is emergent in the network, it is the apophatic silence at the heart of everything, that-which-can-be- pointed-to ... an attempt to do, maybe, possibly, contingently, to point at these things and go but what does it mean? (para 35-36)

While we argue that it is important to keep these two concepts open and wish to not exhaust them by giving them strict definitions, we also understand that readers may want (or need) to start somewhere to better understand these concepts. One place to begin is the very well-written chapter by Klein, where she provides a genealogy of the terms, especially as they originated in the field of art theory and discourse. Moreover, Sweeny's chapter offers a historical perspective to the contested relations between digital artistic and educational practices in the United States, tracing them back to coding structures from the 1940s, hypertexts from the 1980s, and net.art from the 1990s. Reading these two chapters side by side demonstrates well how the post-internet or post-digital as concepts are not traceable to one single, historical point of origin, even though as words their emergence might be possible to locate (as in the case of the term 'post-internet,' which is often credited to artist Marisa Olson). Following Skinner's (1995) claim that concepts may have a long and 
complex life before there are words to describe them, it is possible to say that the semantic and grammatical volatility of the post-internet and the post-digital points to the fact that the history of these two concepts is still in the making.

\section{The Old and New: Theories and Configurations}

In terms of intellectual genealogies, the book brings together older and newer theoretical frameworks to discuss subjectivities, pedagogies, and actions in a post-digital and post-internet world. Like with the history of these concepts, the frameworks utilized by the authors do not form a coherent, unified theory of post-internet, post-digital art or education. Rather, they unfold a rich and interconnected network of texts, thinkers, artworks, technologies, and materials in which artists, educators, curators, and academes currently navigate-or perhaps the network that navigates them.

There are, of course, theoretical points of convergence. For example, many of the authors, including Hahn, Meyer, Knochel, and Schütze, discuss the post-digital as it is related to posthumanism, Actor Network Theory (ANT), and new materialism, in order to better understand the co-formation of human and nonhuman actors within social and ecological configurations of the present. The topicality of these frameworks is understandable, given that they offer a rich language to address the mutable landscape to which the post-internet and the post-digital refer. Yet, the authors in this collection demonstrate the importance of reading these concepts vis-à-vis theories, writings, and artworks also aside from the socalled usual suspects of posthuman thought (Barad, Bennett, Deleuze, Latour, etc.). These constellations of multiple genealogies of thought and practice include Björk's significant attention to Brecht's concept Verfremdung when discussing post-internet art education in lower secondary school in Finland, Meyer's focus on Lacan's Borromean knot when theorizing networked subjectivity, and Rousseau's and Sternfeld's use of Freire when discussing critical practices of education and digital commons. The same applies to Smith's contribution, which offers a strong case for opening the discussion of post-internet art beyond White artists and their narratives of the Internet. Indeed, this may be another way to understand how post-internet is 'all over.'

As editors, it has been our hope that the various conceptual configurations of the post-internet and post-digital included in this book generate 
a network of existing and emerging theories and practices where it is possible, and even desirable, to pair an in-depth investigation of the educational potentials of the doubt (leading to digital glitches), as Grünwald offers in his chapter, with Slotte Dufva's discussion of creative coding as composting- two texts that guide the reader to move within an open landscape between Haraway and vaporwave. Similarly, chapters by Kommoss, Kolb, and jagodzinski invite the reader to reflect on the aspects of the body and touch in post-internet, post-digital art and education; a topic that acquired a whole new relevance and meaning in the wake of Covid-19 pandemic that hit the planet while this book was being written. Ranging from jagodzinski's deep engagement with thinkers like Virilio and Stiegler, Kolb's attention to mediated as well as mediating abilities and gestures of the body, to Kommoss's discussion of sex and intimacy in the digital era, the variegated concept of the post-internet, post-digital body that emerges from these chapters is anything but fixed, or even something that can be claimed completely new or hopelessly old. As in the Internet itself, the old and the new are intimately entwined and have the potential to meet in unexpected constellations. This being said, we hope that the timeliness of this book stays true to the narrative that begins this introduction and yet simultaneously encourages both present and future readers to look beyond what it describes. This includes different ideas of teaching, practice, and pedagogy.

\section{Pedagogical Observations, Suggestions, and Teaching Practices}

This goes to the digital immigrants: The dominant culture of Next Art Education is the culture of the digital natives. It is a culture that is emerging in this very moment. We do not have any experience here. (Meyer, 2014, para 6)

When Torsten Meyer wrote these lines as part of "Next Art Education. 9 Essential Theses," the iPhone 5 was new. Since then, new digital cultures have emerged as well as new technology. Following up the nine essential theses that Meyer presented back then, we have to accept the 'internet state of mind.' In 2020, we already reached the 'post-digital state of mind'. We (as educators, researchers, and so on) should deal with it, as one currently popular meme format has it. But what does this exactly 
mean? The research group, Post Internet Arts Education research, initiated by Torsten Meyer at the University of Cologne has been researching and working on digital and post-digital art education since 2015 and, therefore, a major contribution to basic research on post-internet art and post-digital culture in this book stems from that research group. Focusing on the changed conditions for art education and cultural media education in the domain of 'Internet state of mind,' this group brought together art, media, and cultural studies, raised research and pedagogical questions, and created a transdisciplinary context for research and teaching. However, until this book, most of the available publications from the members of the group were in German, for example, Eschment et al. (2020), Klein and Noll (2019), Meyer and Jörissen (2014).

Apart from those publications in German, some members of the research group, in 2017, developed MYOW-Workbook Arts Education (Klein et al., 2020), an Open Educational Resources (OER) platform for innovative concepts of art education, gallery education, and cultural media education with special emphasis on current media culture(s) and post-internet art. In this OER, practical concepts of participants in the field of art and cultural education publish their teaching methods in order to address art teachers, cultural educators, and practitioners of cultural media education. Considered as a resource and action-based research, different agents of art education cooperated, developed, and made available innovative concepts of art lessons and cultural media education in the context of digitalization. With this outreach platform, other teachers were invited to use the methods, reflect on them and participate as well. In the post-internet, post-digital age, it makes total sense that this is how a 'workbook' for digital art education works.

One might argue that different post-digital perceptions and usage have something to do with different generations. In a sense, the post-digital is not new-it just works differently for different people. As Tomi Slotte Dufva demonstrates in his chapter with the exercise 'A week in hell,' when students are asked to use different digital tools and software than they have been accustomed to, it becomes clear how diverse the use of technology and software is and yet at the same time conservative as well. As soon as we are asked to shift slightly our familiar paths in the digital world, often tools and software become nearly unusable or useless (for example, might you imagine shifting your keyboard from a Windows system to Mac, or vice versa?). 
However, it is not only about the things we are familiar with or used to using. The post-internet state of mind in education mobilizes a reflection on how power relations can be addressed or commented on-be it with humor or subversion. One example would be memes, which are widely circulating combinations of images (still or moving) and texts. Memes are not only easy to reproduce and distribute, but just as easy to produce by oneself. Memes offer an ingenious platform for commenting on everyday things and events, often in a humorous way. But memes are not only used by young people, and, of course, not just for fun. They are also used for overt political purposes including specific right-wing propaganda (Lingg \& Schmidt, 2020). In addition, there are activist meme accounts that consciously use memes to convey feminist, anti-racist, intersectional, and other progressive content. What we can learn from memes is that a form of communication first used by so-called internet nerds became mainstream and political in a very short period of time, and as Schütze (2020) points out, part of national politics in the United States.

In addition to a post-internet and post-digital state of mind, there is another global shift: Covid-19. During this global pandemic, that started in early 2020, followed by national lockdowns in most countries in the global north, education began to move to 'online' only. This significant shift, especially for art education, sparked various reactions. For example, there was the denial of the possibility to teach any so-called creative design activities online. In addition, there was a great need to collect and share information on methods, didactic concepts, Open Access Databases, Open Education Resources, and Open Source Software that students could connect to and afford. There were strategies to collect this information in publicly accessible documents, where main topics of digital art education and best practice examples were continuously linked and shared, e.g., by Bali and Zamora (2020), Syjuco (2020), Kolb (2020), and Shared Campus (2020). While this practice existed before Covid-19, the global pandemic seemed to help to collect and increase the diversity of media in digital teaching and facilitate the entry, or changeover, to digital teaching formats through a variety of examples-and even to help organize people. As Kolb points out in her chapter, digital art teaching is possible and not second best, even if, and especially because, the body is not involved in the same way than in an analogue setting. Therefore, all the authors in this book, one way or another, believe digital art teaching needs rethinking. To take it even further, this process might even lead to unlearning in educational futures. 


\section{Aвоut This Book}

Beyond this introduction, this book is divided into three parts. Part I: How did we get here? Historical, theoretical, critical, and futureoriented perspectives on post-digital and post-internet art \& education consists of five essays. The first one is Kristin Klein's, Post-Digital, Post-Internet: Propositions for Art Education in the Context of Digital Cultures. Klein addresses the concept of digitalization and post-internet acts as symptomatic descriptors of digitally permeated cultures. Klein explores them both through a deep genealogy, as a technological process embedded in social, political, and historical interrelations. Similar to other authors in this book who explore these concepts, Klein references important scholars and artists, such as Barad (2007), Bridle (2013), Latour (2005), Manovich (1999), Olson (2012), and Vierkant (2010). Starting from a broad understanding of each concept and its interdependencies, Klein extends the discussion through four theses, specifically concerning aesthetic aspects. They are (1) distributed artworks, (2) hybrid subjects, (3) fluid materiality, and (4) blind spots. Each thesis leads to a proposition for art education dealing with digital and post-internet cultures. Klein concludes her chapter by highlighting art education's potential in reflecting on digital and post-internet cultures, and in developing new models and methodologies for practical application.

The next essay is by Robert Sweeny. In Post-Internet Art and PreInternet Art Education, Sweeny starts by first describing the early history of the Internet, using historical and familiar concepts from Bush (1945), Castells (1996), and Manovich (2001), and argues that forms of interaction and engagement facilitated by this history have led to a post-internet condition. By inquiring into the history of (North American) art education in a networked era, Sweeny describes what post-internet art, as a distributed structure of knowledge formation, might offer. For example, Sweeny describes the release of Netscape Navigator in 1994 as allowing Internet access to an audience beyond academia, and points to numerous North American art educators who took advantage of this hypertext software. While he rightly points out that the Internet was used commercially and artistically well before Navigator, it did open up possibilities for art education that were previously underdeveloped as decentralized networks. Sweeny not only provides a list of art educators who used Internet technology to challenge the field, but also lays bare the divide between formal 
schooling, which is generally centralized, and the decentralized network of what one might call de-schooling.

Sweeny points out that post-internet art and its antecedents represent a challenge to previous artistic concepts that tended to view the utilization of networked digital technologies as either the fulfillment of utopian fantasies of ego destruction, or the dystopian realization of a posthuman nightmare. Sweeny specifically cites McHugh (2010) as someone who, early on, was highly critical of post-internet art. After referencing numerous artworks, Sweeny argues that, again, for formal schooling, there was a force that did not allow fully allow art education to fulfill its potential in a decentralized system (regardless of all the talk of rhizomatic structures). Sweeny ends his essay by suggesting that art educators might be attentive to the aspects of the internet that are most frustrating, most confusing, and most troublesome, and look to the ways that daily life folds together online and offline interactions in increasingly complex and confusing ways.

The third essay is an attempt to provide a broad and critically theoretical understanding of the particular concepts related to post-digital and post-Internet. In his essay, A Meditation on the Post-Digital and Post-Internet Condition: Screen Culture, Digitalization and Networked Art, jan jagodzinski problematizes the history and current state of screen culture, digitalization, and networked art. jagodzinski draws in large part on the theories of Virilio (2000) and Stiegler (2018), and highlights some of the difficulties they have articulating conceptual discourse about the current speed of technologies. Throughout his essay, jagodzinski also refers to the work of Deleuze and Guattari (2001), to make more complex the concepts, and argues that the contemporary post-media condition shapes the post-digital and post-Internet condition, where the media image dominates across screens and interfaces. Media convergence, jagodzinski states, is where every mass media eventually emerges to a point of becoming one medium due to the proliferation of hybridized communication technologies. Similar to Sweeny, jagodzinski reviews networked art installations as exemplars of resistance, that exemplify one aspect of the networked digital image, this time in relation to the concerns raised by Virilio and Stiegler. In the end, jagodzinski argues that there is 'no going back' to analog. He ends his essay on a question mark as to where to turn to next, for an art and education future.

The fourth essay in this section is by Konstanze Schütze, Bodies of Images: Art Education after the Internet. In her essay, she explores a 
series of thought experiments for an investigation of what one casually calls the image. By using the example of Internet memes, circulating political imagery, formations of classics in art history, as well as contemporary art, images are reintroduced as entities embedded in complex structural realities that are both driving and driven forces of culture. In this endeavor, Schütze renders them as bodies compiled from versions of themselves (bodies of images), explored as embedded in dissemination processes (memeplexes), and hence contoured as highly effective structures with sophisticated potential for transformation (image objects). She uses three major theoretical concepts that also resonate with other essays in the book (meme theory, object-oriented ontology, and network effects) for thinking through the re-interrogation of the image. In addition, Schütze's suggestion is that images are bodies, and should be read as entities that actively, or inactively, form structural assemblages and maintain energetic human and nonhuman constellations, echoes jagodzinski's 'tech-no-body,' albeit in a more productive claim. In the end, Schütze sketches a professional habitus is in which art educators are experts for image relations.

The final essay in Part I is Post scripts in the present future: Conjuring the post-conditions of digital Objects, by Aaron Knochel. Here, Knochel navigates the post-conditions of digital objects, from post-media to postinternet. As with the previous chapters, Knochel engages with theorists such as Deleuze and Guattari (1987), and explores how might making and learning, in art and media education, respond to pervasive connectivity that blurs online and offline distinctions. This theme-online and offline-again, is pervasive throughout the book, and Knochel offers his unique perspectives on speculating a future of algorithms, connectivity, and issues of access. In addition, Knochel makes an argument to advance a range of theoretical tools that may provide insight as to the immanent qualities of data and connectivity that impact making and learning in the arts has made. Similar to other authors in this collection, he focuses on posthumanism and post-theories constructed to provoke the dynamism of materiality. His distinctive take on materiality focuses on digital objects that are conceptualized to understand new opportunities for contemplating artists working in 3D modeling and digital fabrication. Knochel offers insights into the possibility of making meaning in this post-digital moment.

The next grouping of essays belongs to Part II: Why is this important for art education? Transdisciplinary networks, research, and 
subjectivities of the post-digital and post-internet. The first chapter in Part III is a dialogue between Grégoire Rousseau and Nora Sternfeld, Educating the Commons and Commoning Education: Thinking radical education with radical technology. Both authors understand education as a universal right and public good, especially through Sternfeld referencing her influence by Freire (1970), hooks (1994), and Laclau and Mouffe (1985), but also recognizing current forms of education as increasingly facing the processes of economization and privatization. Rousseau, on the other hand, discusses technology as understood as a common means of production when collaboratively developed, as demonstrated in part by Stadler (2013), but at the same time also makes the argument that it is taken away from the public and put into corporate hands. The dialogue comes in the form of a conversation that investigates the question of shared and common knowledge from the perspectives of an educator and an engineer, respectively. The back and forth between Rousseau and Sternfeld explores necessary convergences in radical practices of commoning, and possible future strategies for education and Open Technology. They ask how new models can challenge the neoliberal agenda and move away from established policies, and how a collective re-appropriation of the means of production could emerge within a post-digital society.

The second essay Part II is A new Sujet/Subject for Art Education by Torsten Meyer. In this important essay, Meyer first reviews some fundamental ideas of newer theoretical trends such as Actor Network Theory, Speculative Realism, Object Oriented Ontology and Posthumanism, that have been brought to bear in new generation of (post-internet) artists who no longer regard the radical change in the socio-technical conditions of digital media cultures as something special or new. This mirrors some of the previous discussions by authors such as Knochel, who focused on nonhuman actants and actors in art education, digital software, and art, and Schütze, who spent a significant amount of time referring to image objects, active objects, objects with agency, and especially compound objects. In addition, other authors in this book, such as Hahn, discuss new materialism, and the dualistic categorizations such as subject and object, and Klein considers digital transformation and reformation possibilities, such as digital materiality as an important area of research in art education. Like Meyer, all these authors refer to different contemporary 
theories on materials, nonhuman actors, and objects as areas in art education that acknowledge the seriousness and import of digital things and the idea that networks are not only digital.

As pointed out above, Meyer argues that these ideas have leaked into art education and also the very concept of what constitutes a 'subject.' $\mathrm{He}$ contends that the assumption that the humanistic conception of the human individual as a subject, and the associated understanding of education in modernity, no longer matches neither with the artistic practices based on collaborative networked socio-technical processes that can be observed in the post-internet culture. He states that changing mediality leads to changing subjectivity. Based on findings of the Cologne-based research project Post-Internet Arts Education Research, and using Lacanian and other theories, Meyer introduces the figure of the Sujet to make plausible a perspective on art-based learning processes that is appropriate to the respective overall situations in which these processes (can) take place. Outside of the Cologne-based group, Meyer's work with Lacan also falls in line with jagodzinski's work on new concepts of the subject (2007, 2012, 2017, 2019, 2020).

The subsequent essay in Part II is New Intimates, by Paula Kommoss. In this compelling essay about love, touch, sex, and most importantly the concept of intimacy, Kommoss considers how contemporary digital technology is dramatically changing the ways in which each is perceived and manifested. She argues that to be able to stay in touch, one is dependent on virtual forms of communication through computers and smartphones. These modes of online communication are increasingly generating a paradox of physical anonymity and virtual intimacy. Kommoss makes the case that increasing touch-responsiveness of tablets responds to the current concern that through a constant touching of the screen the human touch becomes redundant (whether that concern is warranted or not). Nevertheless, as she demonstrates through her deep interpretation of multiple post-internet artworks, including Trecartin, Mills, Stark, and Atkins, the notion of touch remains relevant, allowing for a critical investigation of the use of physical tactility within the contemporary art world. In addition, Kommoss takes a close look at the workshops of the educational duo soppa\&bleck to offer an insight into art education's approach toward the digital, and thus intimacy. In the end, Kommos's chapter provides both a deeply theoretical approach and interprets contemporary post-internet art from through a range of approaches to bodily closeness in the post-digital age. 
The next essay is Notes on Corpoliteracy: Bodies in Post Digital Educational Contexts, by Gila Kolb. The essay is grounded in the belief that learning and knowledge inscribe themselves into the body. Kolb, similar to Kommoss, argues that more attention to the body and touch should take place, especially in educational programs, and certainly as teachers and learners increasingly meet in digital learning environments. The essay is both a critical reflection on different ways we use 'the body' (or ways we are supposed to use the body) in formal education, and an exploration of current digital teaching and learning settings in the times of Covid-19. Kolb offers educators five examples of how bodies are read and understood differently in the digital world and asks us to reconsider our practices now, and in the future.

Following Kolb's chapter is an essay on the perspective of media education theory and aesthetic education. In his essay, Aesthetic Practice as Critique: The Suspension of Judgment and the Invention of New Possibilities of Perception, Thinking, and Action, Manuel Zahn discusses some considerations of aesthetic practice or what he calls 'media-critical practice.' He describes media-critical practice as a reflexive-transformative practice with and in media, that no longer has a distanced, self-reflexive and rational critique of media, or media use. Similar to other authors, Zahn uses multiple contemporary and traditional theorists in his rethinking of critique, including Adorno (1959), Deleuze and Guattari (1987), Rancière (2006), as well as jagodzinski's (2017) work on art and education after Deleuze and Guattari.

In addition to the aforementioned theorists, Zahn focuses heavily on Foucault's (1992) concepts of critique and apparatus, further developed by Badura's (2011) concept of aesthetic apparatuses. Like Kommoss, Zahn then approaches Trecartin's post-internet artwork. Zahn explores 'Re'Search Wait'S' (2010) and makes the case that post-internet aesthetic practices require a new language of critique when dealing with the relation between humans and contemporary media-cultural environments. That is, like Foucault's concept, critique is interested not only in elements and rules that constitute the social game of subjectivations and their regularity, but above all in how these rules can be changed. From this perspective, subjects no longer intentionally deal with media, but first and foremost become subjects in relation to medial apparatuses, as discussed in a different way in Meyer's chapter.

Following Zahn's text is the essay by Schmidt: What is the 'Poor Image' Rich in? Schmidt presents the potential of 'poor images,' a term coined 
by Steyerl (2009) for a contemporary critical mediation of art, especially in schools. Originally, Steyerl described the 'poor image' as a 'copy in motion.' This meant a visual replica of an original image meandering through the Internet, gradually losing information. Schmidt takes up this concept ten years after later and argues that they have become part of our everyday visual practice. Schmidt reflects on her own teaching practices with poor images, and how she used them as a potential starting point, not only as inspirational material, but also as raw material for further processing. After starting her own Instagram account @ poorimagearteducation, Schmidt asked students to create an art meme based on works from art history.

Two students in her course used digital cut-outs from paintings by Hieronymus Bosch and created a speculative story about the painter's supposed inspiration for his fantastic figures in the painting. They reenacted these figures with their own bodies, and with objects found at the university, which they quickly and intentionally assembled into new 'bad' collages using Photoshop. Then, they juxtaposed these with the corresponding cut-outs. The students claimed they were original themselves, on which the art historical icon is based. In doing so, they intentionally use a trashy pictorial aesthetic and thus expose the traces of their working method. They transformed the image into a poor image, but also made a poor image out of themselves, using hashtags, such as \#nofilter, \#italiannana, and \#deathbychocolate. In the end, Schmidt makes the case that because, in part of numerous developments, these poor images are no longer poor the way Steyerl once described them, and asks the readers to consider to what extent these images are relevant for art education.

The final section of the book is Part III: How to deal with it being all over and how can we create educational futures? Classroom and pedagogical practices examples of post-digital and post-internet art education. The first essay in the section is Educating Things: Art Education beyond the Individual in the Post-Digital, by Annemarie Hahn. In her essay, Hahn argues, similar to other authors, that current digital infrastructures have not only profoundly changed the way people communicate with each other, but also the physical conditions in which people relate to other people, people relate to things, and also things relate to things. In doing so, Hahn also builds on some of the same theorists as other authors in this book, such as Barad (2007), Latour (2014), and Foucault (1969). She makes the point that these emerging alliances between people and things have an impact on the relationships between 
human and nonhuman actors, and thus also on concepts of individual subjectivity. While subjectivity is also a pervasive topic, the essay, however, exclusively focuses on the exhibition "Co-Workers - Network as Artist" at the MAM in Paris (Lykkeberg, 2015). Using neo-materialistic theoretical approaches, Hahn argues that a new relationship can be observed between the artist-subject and the art-artefacts, which places the materials in the focus of the dissonance. This displacement is to the disadvantage of the individual artist-subject. In her chapter, these theoretical considerations are exemplified by an examination of the relations between people and things in the exhibition, particularly focusing on the understanding of digital materiality.

The second essay is Toward an anti-racist and anti-colonial postinternet curriculum in digital art education, by Timothy J. Smith. In the article, he examines how reframing post-internet art through antiracist and anti-colonial lenses in digital art curriculum might cultivate critical and transformative artist practices for students. As discussed in the beginning of this chapter, anti-racist and anti-colonial approaches may offer frameworks for critically analyzing identity, ideology, and power relations by decentering the art canon from the Global North, and qualitatively shifting curriculum toward critical dialogues and social action. Through a retrospection of Smith's own active and ongoing transformation as a teacher, as well as through an analysis of Tabita Rezaire's post-internet art practice, this essay builds a pedagogical foundation for students to generate their own critical consciousness in learning and artmaking through a digital art curriculum.

Following Smith's essay is the third in Part III, Embracing Doubt: Teaching in a Post-Digital Age, by Jan G. Grünwald. In the article, he makes the case that schools are still mostly concerned with transmitting a canon of what is important and with it produces a certain type of teacher. According to Grünwald, when teachers have to try to create a situation in class, such as imagining school as a futuristic endeavor, something new can emerge. However, since the concept of the teacher seems to remain that she or he is the one who owns knowledge (in contrast to students who don't) it is understandable that teachers have doubts about creating a situation out of the usual boundaries of 'I know - you don't.' In this essay, Grünwald argues that if we want to teach adequately for the postdigital age, we have to embrace doubt as a force that is anti-status quo, and falls out of the usual teleological approach of teaching. According to Grünwald, this approach translates into practice because the teacher does 
not know which outcome an educational situation will have, they must improvise. The essay focuses on this approach in the classroom, which denies classical power structures and the need for a dominant leadership of the teacher.

The next essay in this section is by Tomi Slotte Dufva, Creative Coding as Compost(ing). Slotte Dufva focuses on creative coding practices within a university-level art education context. Drawing from earlier literature and combining it with current research, his essay takes a feminist approach to creative coding and examines the importance and possibilities of different code-related art educational practices in the post-digital world(ing)s. Slotte Dufva's essay discusses how the post-digital takes place by using compost as a metaphor for art education practices. More specifically, this essay introduces three examples from courses taught at Aalto University that together form the digital compost: humus, care, and waste. Slotte Dufva's chapter closes with the discussion on further feminist approaches within post-digital within art education.

The next text is Helena Björk's essay, Post-Internet Verfremdung. Her work also discusses curricula. Björk presents a school assignment as a possible approach to online visual culture, though creating Instagram fiction. Björk argues that the ease of uploading images on Instagram has meant that a whole generation grows up paying closer attention to visual language. At the same time, Instagram and other social media have come to dominate visual culture to the extent that we might consider how to unlearn what they may have taught us. In her essay, the internet is seen not only as a vital part of visual culture but also as a site of learning. When students create Instagram fiction, Björk argues, we can understand how social media operate both visually and socially. Parody and estrangement, or the Brechtian Verfremdungseffekt, are examples offered in this essay to examine this phenomenon, and possibly activate critical thinking.

To conclude this introduction, we raise the issue of generational shifts. For example, Meyer (2020) explains that when he asked his students and also his own children (of the same age) to communicate via email (as the editors and authors did when putting this book together), they "tell me clearly: I only use email when I need to communicate with old people. Boom" (para 10). According to this logic, the book you hold in your hands is already outdated since the moment it was printed, created as a PDF, or made ready for downloading on some device to read. Of course, that does not mean that there are not many good reasons to read it, in whatever manner. Similar to schooling, just because is often based on a 
system that passes on knowledge rather than one that creates knowledge, or challenges the very notion of knowledge, it doesn't have to stay that way.

The theoretical work and pedagogical examples in this book might help you to deal with a post digital state of mind. It encourages readers to shift ideas of criticality when teaching art in the post-digital and post-internet era, and to broaden the understanding of teaching and learning beyond one's own generational logics. The editors and authors of this book want to reach you, even if you see this book it in the same way Meyer's students see emails, with our desire hope that you will make something with and from it. We hope that it not only meets new futures, but also helps to create them, again and again, even if, and especially because 'it's all-over.'

\section{Notes}

1. On the app Jodel, texts and pictures can be published, read and commented regionally and anonymously.

2. See: Michael Seemann, Michael Krell (2017) Digital Tribalism-The Real Story About Fake News. https://www.ctrl-verlust.net/digital-tribalismthe-real-story-about-fake-news/.

\section{REFERENCES}

Adorno, T. W. (1959). Theorie der Halbbildung. In Gesammelte Schriften, Bd 8. Soziologische Schriften I (pp. 93-121). Suhrkamp.

Badura, J. (2011). Ästhetische Dispositive. In Critica-Zeitschrift für Philosophie und Kunsttheorie, H. 2, pp. 2-14.

Bali, M., \& Zamora, M. (2020). Crowdsourcing teaching online with care. https://bit.ly/onlinewithcare.

Barad, K. (2007). Meeting the universe halfway: Quantum physics and the entanglement of matter and meaning. Durham University Press.

Bridle, J. (2012, March 15). \#sxaesthetic. https://booktwo.org/notebook/sxa esthetic/.

Bridle, J. (2013). The new aesthetic and its politics. https://booktwo.org/not ebook/new-aesthetic-politics/.

Bush, V. (1945, July). As we may think. Atlantic Monthly, 176, 101-108.

Castells, M. (1996). The rise of the network society. Blackwell.

Deleuze, G. (2001). Pure immanence: Essays on life (A. Boyman, Trans.). Zone Books. 
Deleuze, G., \& Guattari, F. (1987). A thousand plateaus: Capitalism and schizophrenia (B. Massumi, trans.). University of Minnesota Press. (Originally published in 1980).

Dick, J., Meyer, T., \& Moormann, P. (Eds.). (2016). Where the magic happens: Bildung nach der Entgrenzung der Künste. Kopaed.

Eschment, J., Neumann, H., Rodonò, A., \& Meyer, T. (Eds.). (2020). Arts education in transition: Ästhetische Bildung im Kontext kultureller Globalisierung und Digitalisation. Kopaed.

Foucault, M. (1969). Was ist ein Autor? In F. Jannidis (Ed.), Texte zur Theorie der Autorschaft (pp. 198-229). Reclam.

Foucault, M. (1992). Was ist Kritik?, übers. v. Walter Seitter. Merve.

Freire, P. (1970). Pedagogy of the Oppressed. Continuum.

hooks, b. (1994). Teaching to transgress: Education as the practice of freedom. New York.

jagodzinski, j. (2007). Without title: On the impossibility of art education: Art as becoming-Posthuman. Canadian Journal of Education through Art, 5(2), 6-15.

jagodzinski, j. (2012). Sk-interfaces: Telematic and transgenic art's post-digital turn to materiality. In W. Sützl \& T. Hug (Eds.), Activist media and biopolitics: Critical media interventions in the age of biopower (pp. 81-99). Innsbruck University Press.

jagodzinski, j. (Ed.). (2017). What is art education? After deleuze and guattari. Palgrave Macmillan.

jagodzinski, j. (2019) Schizoanalytic ventures at the end of the world: Film, video, art and pedagogical challenges. Palgrave-Springer.

jagodzinski, j. (2020). Pedagogical explorations in a posthuman age: Essays on designer capitalism, eco-aestheticism, visual and popular culture as west-east meet. Palgrave-Springer.

Jörissen, B., Meyer, T. (Eds.) (2014). Subjekt medium bildung. Springer/VS Verlag für Sozialwissenschaften.

Klein, K., Kolb, G., Meyer, T. \& Schütze, K. (Eds.). (2018). MYOW-Workbook arts education. https://myow.org/.

Klein K., Kolb, G., Meyer, T., Schütze, K., \& Zahn, M. (Eds). (2020). Postinternet arts education texte. https://piaer.net/texte/.

Klein K., \& Noll, W. (Eds.). (2019, October 1). Postdigital landscapes: Kunst und Medienbildung in der digital vernetzten Welt. https://zkmb.de/sammlung/ postdigital-landscapes/.

Knochel, A. (2011). Seeing non-humans: A social ontology of the visual technology: Photoshop (Doctoral Dissertation). Columbus, OH, Ohio State University.

Knochel, A. (2016). Photoshop teaches with(out) you: Actant agencies and nonhuman pedagogy. Visual Arts Research, 42(1), 71-87. 
Kolb, G. (2020). Eine kunstpädagogische Ressourcenliste. https://tlp.de/KunstR essourcen.

Kosinski, J. (director). (2010) Tron: Legacy. Walt Disney Pictures.

Laclau, E., \& Mouffe, C. (1985). Hegemony and socialist strategy: Towards a radical democratic politics. Verso Books.

Latour, B. (2005). Reassembling the social-An introduction to ANT. Journal of Chemical Information and Modeling. https://doi.org/10.1017/CBO978 1107415324.004.

Latour, B. (2014). Eine neue Soziologie für eine neue Gesellschaft. Einfüluung in die Akteur-Netzwerk-Theorie. Suhrkamp.

Lingg, S., \& Schmidt, H. (2020). COMING BACK FROM IBIZA. Der Instagram-Account Ibiza Austrian Memes als Case-Study für intersektionalen Meme-Aktivismus und Vermittlung - basierend auf einem Gespräch mit Anahita Neghabat. In S. Lingg \& H. Schmidt (Eds.), SFKP e Journal Art Education 18. https://sfkp.ch/artikel/coming-back-from-ibiza

Lisberger, S. (director). (1982). Tron. Walt Disney Pictures.

Lykkeberg, T. (2015). Le réseau comme artiste. In Musee D'Art Moderne de la Ville de Paris (Ed.), Co-Workers. Le résean comme artiste. Exhibition-Catalogue (pp. 20-23). Musee D'Art Moderne.

Manovich, L. (1999). Database as symbolic form. Convergence: The International Journal of Research into New Media Technologies 5(2), 80-99. doi:https:// doi.org/10.1177/135485659900500206.

Manovich, L. (2001). The language of new media. MIT Press.

McHugh. (2010). Post-internet art (blog). https://122909a.com.rhizome.org.

Meyer, T. (2014). Next art education: 9 essential theses. In T. Meyer \& G. Kolb (Eds.), What's next? Art education (p. 218). Kopaed. https://whtsnxt. net $/ 245$.

Meyer T. (2020). Nach dem Internet. In J. Eschment, H. Neumann, A. Rodonò, \& M. Meyer (Eds.), Arts education in transition, Zeitschrift Kunst Medien Bildung. https://zkmb.de/nach-dem-internet/.

Olson, M. (2012). Postinternet. Foam Magazine, Issue 29, 59-63.

Rancière, J. (2006). Die Aufteilung des Sinnlichen. B-Books.

Scherpe, M. (2011, February 1). Art in Berlin: Carson Chan. Stil in Berlin. https://www.stilinberlin.de/2011/02/interview-carson-chan.html.

Schütze, K. (2020). Bildlichkeit nach dem Internet. Kopaed.

Skinner, Q. (1995). Language and political change. In T. Ball, J. Farr, \& R. L. Hanson (Eds.), Political innovation and conceptual change (pp. 6-23). Cambridge University Press.

Späti, D., Krämer, N., \& Jetzer, V. (Eds.). (2020). Shared Campus by a collective of art schools. https://shared-campus.com/2020.

Steyerl, H. (2009). In defense of the poor image. e-flux. https://www.e-flux.com/ journal/10/61362/in-defense-of-the-poor-image/. 
Stiegler, B. (2018). The neganthropocene (D. Ross, Ed. \& Trans.). Open Humanities Press.

Syjuco, S. (2020). PUBLIC PEDAGOGY: Shared syllabi from college art teachers, for college art teachers. https://docs.google.com/spreadsheets/d/11HEFU hXVDG6Bil9dhdr6-I7C19j6ndORvNz81oH4ndQ/edit\#gid=0.

Tavin, K., \& Tervo, J. (2018). How soon is now? Post-conditions in art education. Studies in Art Education, 59(4), 282-296.

Trecartin, R. (Writer \& Director). (2010). Re'Search Wait'S [Video]. United States.

Virilio, P. (2000). The information bomb (C. Turner, Trans.). London: Verso.

Vierkant, A. (2010). The image object post-Internet. https://jstchillin.org/artie/ pdf/The_Image_Object_Post-Internet_us.pdf.

Open Access This chapter is licensed under the terms of the Creative Commons Attribution 4.0 International License (http://creativecommons.org/licenses/ by $/ 4.0 /)$, which permits use, sharing, adaptation, distribution and reproduction in any medium or format, as long as you give appropriate credit to the original author(s) and the source, provide a link to the Creative Commons license and indicate if changes were made.

The images or other third party material in this chapter are included in the chapter's Creative Commons license, unless indicated otherwise in a credit line to the material. If material is not included in the chapter's Creative Commons license and your intended use is not permitted by statutory regulation or exceeds the permitted use, you will need to obtain permission directly from the copyright holder.

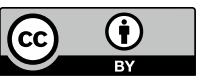

